Article

\title{
Gender Division of Domestic Labor in Post-Socialist Europe (1994-2012): Test of Class Gradients Hypothesis
}

\author{
Daria Ukhova
}

Bremen International Graduate School of Social Sciences, University of Bremen and Jacobs University, 28359 Bremen, Germany; E-Mail: dukhova@bigsss.uni-bremen.de

Submitted: 29 February 2020 | Accepted: 20 April 2020 | Published: 9 October 2020

\begin{abstract}
This article analyzes changes in the gender division of domestic labor (GDDL) in post-socialist Central and Eastern Europe (CEE), an under-researched region characterized by high levels of inequality in GDDL from 1994-2012. Drawing on the literature on class gradients in the contribution of the genders to domestic labor and their change over time, the article answers two questions: How has GDDL (operationalized as men's relative involvement into routine housework) changed in CEE in the post-socialist period? What has been the role of class (operationalized as respondents' education and household income) in shaping GDDL in CEE in the post-socialist period? Data for the article comes from the 1994, 2002, and 2012 waves of the International Social Survey Program on Family and Changing Gender Roles from six CEE countries, i.e., Bulgaria, Czechia, Hungary, Poland, Russia, and Slovenia. The findings suggest that net of individual and interactional-level factors, inequality in GDDL in the CEE region did not change substantially during the post-socialist period. The analysis also shows, however, that trends of inequality in GDDL among different classes were idiosyncratic, and this underlay the overall lack of movement towards greater equality.
\end{abstract}

\section{Keywords}

CEE; domestic labor; gender inequality; housework; post-socialism

\section{Issue}

This article is part of the issue "Division of Labour within Families, Work-Life Conflict and Family Policy" edited by Michael Ochsner (FORS Lausanne, Switzerland), Ivett Szalma (Centre for Social Sciences, Hungarian Academy of Sciences Centre of Excellence, Hungary/Corvinus University of Budapest, Hungary) and Judit Takács (Centre for Social Sciences, Hungarian Academy of Sciences Centre of Excellence, Hungary/KWI Essen, Germany).

(C) 2020 by the author; licensee Cogitatio (Lisbon, Portugal). This article is licensed under a Creative Commons Attribution 4.0 International License (CC BY).

\section{Introduction}

Domestic labor remains unequally divided between women and men in mixed-sex households in all countries in Europe, further perpetuating gender inequality in access to paid work, political representation, and leisure (Beneria, Berik, \& Floro, 2015). Certain regions and countries, however, are particularly notorious for high inequality in the gender division of domestic labor (GDDL) but have received comparatively little attention from researchers. The study focuses on one of such regions, i.e., Central and Eastern Europe (CEE).

In several recent cross-sectional comparative studies on GDDL, CEE comes up as a special case because, when considering net of individual and couple-level characteristics, there appears to be more "severe domestic inequality" in that region (Aboim, 2010, p. 197) than in Western Europe that such comparisons usually include (Aassve, Fuochi, \& Mencarini, 2014; Aboim, 2010; Treas \& Tai, 2012). What remains unclear, however, is the development of this phenomenon over time (Klenner \& Leiber, 2010). Some studies have recently analyzed changes in GDDL (Altintas \& Sullivan, 2016; Geist \& Cohen, 2011; Hook, 2006, 2010), but trends in CEE countries have not been specifically considered in any of them. Has the stalled socialist gender revolution (Lapidus, 1978) persisted in the post-socialist period? Or has there been a move towards greater equality in 
GDDL, as suggested by aggregate level analyses that have focused on the first post-socialist decade (Crompton, Brockmann, \& Lyonette, 2005; Saxonberg, 2014)? Or, rather, has there been a neo-traditionalist turn, as predicted by some commentators (Watson, 1993)? This is the first set of questions motivating this study.

Focusing on GDDL in the CEE region also has an important theoretical implication. Studies on individualand interactional-level determinants of GDDL demonstrate that models applied to Western countries often have a significantly poorer fit in the CEE (Fuwa, 2004; Mikucka, 2009). For example, such factors of GDDL as time availability and gender role attitudes have been shown to have low explanatory potential in the region (Fuwa, 2004; Mikucka, 2009). Currently evolving research on class gradients (education-and incomerelated) in men's and women's contribution to domestic labor (Gupta, Evertsson, Grunow, Nermo, \& Sayer, 2010; Heisig, 2011; Schneider \& Hastings, 2017), and their change over time (see, for example, the changing differences approach in Sullivan, 2010) could provide an additional explanatory perspective relevant for CEE. With its experience of unprecedented growth of economic and social inequalities in the post-socialist period (see Table 1 in the Supplementary File), CEE provides a valuable case for further testing of these theories. In this article, I draw on and aim to contribute to this emerging literature.

To summarize, this article aims to answer the following questions: How has GDDL changed in CEE in the postsocialist period? What has been the role of class in shaping GDDL in CEE in the post-socialist period?

In the next section, I provide an overview of the theories of GDDL. This is followed by a discussion of what we know so far in this respect about changes in CEE. I then discuss the methodology of this study. The following section presents the results of the analysis by first focusing on the regional trends of inequality in GDDL and then on the country-specific ones. The findings suggest that net of individual and interactional-level factors, inequality in GDDL in the CEE region did not change substantially in the post-socialist period. The analysis also shows, however, that trends of inequality in GDDL among different classes were idiosyncratic, and this underlay the overall lack of movement towards greater equality.

\section{Theoretical Background}

\subsection{Routine Housework as a Cornerstone of Inequality in GDDL}

In this study, I analyze GDDL through the lens of gender division of routine housework. Routine housework remains strongly 'feminine-defined' across countries, with women spending most of their domestic labor time on this type of tasks, while men continue focusing on less mundane and time-consuming 'masculine' non-routine housework, such as DYl, garden work, etc. (Kan, Sullivan, \& Gershuny, 2011). This segregation of domestic tasks has been shown to represent the key barrier to further gender convergence in time use and improvements in gender equality in the domestic sphere (Kan et al., 2011).

Changes in GDDL are best investigated with the help of time-use diaries and time-use surveys (Sullivan, Gershuny, \& Robinson, 2018). In the absence of time-use data (which is the case in the 1994 wave of ISSP), changes in men's relative involvement in routine housework tasks, however, could serve as a good indicator of changes in inequality in GDDL (Crompton et al., 2005).

\subsection{Theorizing Inequality in GDDL}

Most of the research on GDDL to date has been cross-sectional and focused on four key individual- and interactional-level explanations (Davis \& Wills, 2014; Drobnič \& Ruppanner, 2015). First, gender ideology acquired through socialization has been shown to influence GDDL, with men and women that hold more egalitarian gender-role attitudes distributing domestic labor more equally (Aassve et al., 2014; Aboim, 2010). Second, several studies have suggested that partners divide domestic labor according to the time they have available from their work outside the household (Bianchi, Milkie, Sayer, \& Robinson, 2000; Davis \& Greenstein, 2004). Third, partners' relative resources (e.g., income) have been shown to play a role in bargaining about the performance of housework, i.e., the greater the relative advantage of a partner is, the less time he or she would spend on such work (Bianchi et al., 2000; Evertsson \& Nermo, 2007). Finally, the performance of domestic labor has been theorized as a way of 'doing gender' (Bittman, England, Sayer, Folbre, \& Matheson, 2003; West \& Zimmermann, 1987). No real consensus in the literature, however, has emerged regarding the relative explanatory potential of these theories (Bianchi \& Milkie, 2010). In the CEE context, as indicated above, these theories appear to have quite low explanatory power (Fuwa, 2004; Mikucka, 2009).

A relatively more recent stream of research on GDDL has focused on so-called class gradients (education- and income-related) in men's and women's contribution to domestic labor. Higher levels of education have been shown to be associated with more egalitarian GDDL (Esping-Andersen, 2009; Hook, 2010). The effects are usually interpreted in terms of more egalitarian attitudes, values, and ideologies of higher-educated men and women. Differences in the time spent on domestic labor by women and men from lower and higher-income households are explained mainly by differing outsourcing opportunities and differing access to time-saving technology (Gershuny, 2000; Gupta et al., 2010; Heisig, 2011; Schneider \& Hastings, 2017). These studies have primarily analyzed class gradients in housework hours among women rather than differences in GDDL across classes.

Research on changes in GDDL over time has also focused on class gradients in the performance of domestic labor. Sullivan has introduced the term "changing 
differences" to refer to "different changes over time in the contributions to family work of those from different socio-economic and demographic subgroups of the population" (Sullivan, 2010, p. 716). In this article, following Sullivan, I will conceptualize the changing role of class in shaping GDDL as changing differences in GDDL by respondents' education and household income.

In her study, Sullivan (2010) analyzed changing differences in men's contribution to domestic labor and childcare by men's education. She demonstrated that, in the UK and US, over time, lower-educated men caught up with higher-educated men in terms of their contribution to domestic labor. Sullivan interpreted changing differences in differently-educated men's contribution to domestic labor as empirical confirmation of Bourdieu's account of behavioral social changes as originating in the upper strata of society and over time trickling down the socio-economic spectrum (Bourdieu as cited in Sullivan, 2010).

In contrast to changes in education-related differences, assessing the changing differences in GDDL by household income seems to have been neglected. Drawing on the cross-national and cross-sectional studies reviewed above, it is reasonable to assume that the effect of household income on GDDL could be interpreted in terms of the differing outsourcing opportunities, as well as differing access to time-saving technology for households with different incomes. The levels of overall economic development (Gershuny, 2000) and economic inequality (Heisig, 2011; Schneider \& Hastings, 2017) have been shown to moderate those relationships. Significant changes in these macro-level parameters could, thus, be expected to lead to changing differences in men's and women's contribution to domestic labor by household income.

Notably, the studies focusing on class gradients in the division of domestic labor and their variations across contexts and time so far have not focused on CEE. With its experience of rapid economic transformation and acute growth of economic and social inequalities in the last 30 years (for an overview of socio-economic trends in CEE, see Table 1 in the Supplementary File), the region represents a good case for this type of analysis.

\section{Regional Context and Hypotheses}

\subsection{GDDL in Post-Socialist CEE}

The problem of women's double burden of paid and unpaid work is well-documented in the literature on statesocialist countries (Einhorn, 1993; Gal \& Kligman, 2000; Saxonberg, 2014). Although CEE socialist states achieved significant levels of socialization of care (especially, in comparison with their Western neighbors), domestic labor mostly remained a remit of families, and primarily of women within them.

In the first post-socialist decade, a predominant view established in the literature was that unequal GDDL had persisted or even worsened during the market transition. This increased inequality was attributed to certain macro-level changes in the region, such as women's mass withdrawal from the labor market, increasing job demands on those women who did not withdraw, and the state's retrenchment from the provision of care services and social benefits that took place during the 1990s (Ashwin, 2006; Pine, 2002; Pollert, 2003). Among the analyzed countries, the above trends were most visible in Russia (which also experienced the largest recession in that period), and least in Slovenia (see Table 1 in the Supplementary File). Some scholars also argued that calls for 're-traditionalization' coming from the new political leaders could have impacted gender attitudes and gender relations and led to more unequal GDDL (Nikolic-Ristanovic, 2002; Takács, 2013; Watson, 1993). This assumption about increased gender inequalities in the domestic sphere, however, has been underexplored in a comparative quantitative manner.

In the 2000s, there was hardly any research on GDDL in CEE (Klenner \& Leiber, 2010). We know, however, that some of the negative macro-level trends that were thought to underpin the increase of inequality in GDDL in the first post-socialist decade significantly slowed or even reversed (see Table 1 in the Supplementary File). Women's participation in the labor force, public spending on family benefits, and the percentage of children enrolled in pre-school institutions in $\mathbf{2 0 1 2}$ were higher than in 2002 in nearly all of the analyzed countries. The Gender Inequality Index shows that, in the 2000s, at least in Russia and Bulgaria, a move towards lower macro-level gender inequality, which has been shown to be related to more equal GDDL (Fuwa, 2004), also accelerated. It is reasonable to assume that all these changes combined with the relatively increased prosperity of the households could have alleviated the burden of domestic labor for CEE households and reduced the extent of gender inequality in its division. This leads me to hypothesis 1 :

Net of individual and interactional-level factors, inequality in GDDL in CEE increased during the first postsocialist decade and subsequently decreased during the 2000s.

\subsection{Class Divisions in Post-Socialist CEE and Domestic Labor}

There is almost no research on the role of education concerning domestic labor in the socialist period. We do know, however, that the ideology of kulturnost ('culturedness'), a principal marker of educated class habitus under socialism (Salmeniemi, 2012), encompassed a set of values and practices, including patterns of consumption, personal hygiene, etc., which could have impacted volumes of domestic labor and its division. In one Polish study from the 1970s, partners' education was, indeed, shown to be an important factor of men's contribution to 
domestic labor, and couples with higher education had the most egalitarian GDDL (Lobodzinska, 1977).

Whether education has remained a factor of GDDL in the post-socialist period has not been researched so far. However, a study on attitudinal change in Russia has suggested that educational differences in preferences for male breadwinner/female caregiver model increased during the post-socialist period, with highly educated being increasingly less likely to endorse this model than lower educated (Motiejunaite \& Kravchenko, 2008). It is reasonable to assume that under the condition of increased social and economic inequalities the importance of education-as a source of social distinction-has likely increased also concerning actual GDDL.

In contrast to education, income was hardly an important factor of class difference in the socialist period due to highly compressed wage structures. In the postsocialist period, however, when countries of the region have witnessed an unprecedented growth of income inequality, income and economic capital, in general, have become important class markers (Gapova, 2002). While all the analyzed countries witnessed significant relative growth of economic inequality in the post-socialist period (see Table 1 in the Supplementary File), it is important to note that the increase was much more tangible in Russia, Bulgaria, and Poland.

The role of income in organizing and dividing unpaid work in post-socialist CEE has started being discussed in the literature only recently. In the early 2000s in Russia, household income was shown to be strongly associated both with the volume of domestic labor and the level of gender inequality in its division-poorer households did substantially more of their domestic work, and women in such households shouldered a greater relative share of it than women in the richer households (Balabanova, 2005). Studies on outsourcing of domestic labor and care among the new middle classes in Slovenia, Czechia and Russia (Humer \& Hrznjak, 2015; Redlová, 2012; Rotkirch, Tkach, \& Zdravomyslova, 2012) suggest that when domestic workers and nannies are hired, they take over the part of unpaid work carried out by women.

The above leads me to suggest the following hypotheses:

Hypothesis 2a: Over the post-socialist period, the positive effect of education on the level of equality in GDDL has increased.

Hypothesis 2b: Over the post-socialist period, the positive effect of household income on the level of equality in GDDL has increased.

\section{Method}

Data for this article come from the 1994, 2002, and 2012 waves of the International Social Survey Program (ISSP) on Family and Changing Gender Roles. The ISSP is a unique repeated cross-sectional survey that allows an- alyzing changes in GDDL in CEE over the period of interest. A total of six post-socialist European countries participated in all three waves, i.e., Bulgaria, Czechia, Hungary, Poland, Russia, and Slovenia.

I restricted the sample to those respondents who had a co-resident partner. Because partner's sex is not reported in ISSP, I treated all couples as mixed-sex. I further limited the age group to 18-65 (prime working age) and excluded those who reported that they or their partner were in education (because I could not reasonably control their workload outside the home) or had a permanent illness or disability (in such households distribution of domestic labor is likely to be strongly affected by the physical condition of the partner-but the number of such households was too small to draw any reliable conclusions about this specific group). Multiple Imputation procedure in SPSS 26 was used to estimate values for missing data, following best practices in the field of family research (Johnson \& Young, 2011). Pooled across years and countries, the non-weighted analytical sample size was 11,730 (for country samples see Table 2 in the Supplementary File).

Following the approach used by Kunovich and Kunovich (2008), in the pooled regression, I applied external weights, the goal of which was to equalize the sample sizes across countries within each wave, so that each country would contribute equally to the estimation of slope coefficients. No weights were applied in the country-specific regressions.

\subsection{Dependent Variable}

I used the index developed by Geist and Cohen (2011) to account for changes in the GDDL. The index is based on answers to three questions about routine daily tasks usually performed by women, i.e., laundry, cooking dinner, and shopping for groceries. Only these three questions were consistently included in all three waves analyzed. Respondents stated which partner and how frequently (always, usually, about equal) they performed the task or whether the task was outsourced/performed by a third person. Following Geist and Cohen (2011), I coded the answers as follows:

- -2 "task is always done by the woman"

- -1 "task is usually done by the woman"

- 0 "task is equally shared" OR "done by a third person/outsourced"

- 1 "task is usually done by the man"

- 2 "task is always done by the man"

I then added values for all three tasks. As a result, I obtained a measure of a degree of male relative involvement in routine housework with possible values ranging from minus 6 (all tasks performed by the woman) through 0 (all tasks equally shared) to plus 6 (all tasks performed by the man). Because in all the country-years, mean values of the index were below 0 , in what follows, 
I use men's relative involvement in routine housework and the level equality in GDDL as synonymous terms.

\subsection{Independent Variables and Controls}

The first key variable of interest was the survey year. I used year dummies to analyze changes in the prevalence of couples with different patterns of GDDL over time.

Further key independent variables that should have captured the effects of class on GDDL were household income and respondent's level of education. Household income was measured as the bottom $20 \%$ vs. middle $60 \%$ vs. top $20 \%$ of the country-specific household-size equivalized income distribution (calculated by dividing household income as reported in ISSP by the square root of the household size). Respondent's level of education was measured as low vs. medium vs. high corresponding to ISCED 2011 categories 0-2, 3-4, and 5-6 respectively. Because the 1994 ISSP wave (for all countries) and the 2012 wave (for Russia and Bulgaria) did not include questions on the partner's level of education, I had to use the respondent's education as a proxy of the household's educational level. Where data on both partners' level of education was available, educational homogamy, however, was high (Spearman's coefficient was at least 0.5, but in most country-years exceeded 0.6).

In addition to the above variables, I also included in the models the measures of other individual-and interactional-level factors of GDDL reviewed in the theoretical section. Relative resources were measured by the woman's share of income. Employment statuses of both partners were used as measures of time availability. I differentiated between those working full-time, part-time, and not working for pay. Respondents who were employed full-time and whose partner also worked full-time were the reference category in the models. Respondent's gender role attitudes were captured with an index of gender egalitarianism (Treas \& Tai, 2016) composed of answers to five questions about the level of the respondents' agreement with the following statements: 1) A pre-school child is likely to suffer if their mother works; 2) family life suffers when the woman has a fulltime job; 3) what most women want is a home and children; 4) being a housewife is as fulfilling as working for pay; and 5) a man's job is to earn money; a woman's job is to look after the home and family (Cronbach's alpha $=0.73)$. In the original survey, the answers to each question were given on a 5 -point scale $(1=$ strongly agree to $5=$ strongly disagree). Thus, the higher values of the index (which ranges from 5 to 25 ) indicate more gender-egalitarian attitudes.

I controlled for the sex and age of the respondent, as well as for the household size. Controlling for sex of the respondent allowed to account for potential differences in men's and women's reporting of the gap between their own and their partners' contributions to household labor (Lee \& Waite, 2005). Information on the presence of children in the household was not available in the 1994 wave, and, therefore, was not included. Age, age squared, and household size variables, however, should have captured the 'child' effect, at least, to some extent.

\subsection{Analytical Strategy}

I estimated a series of OLS models. After analyzing the descriptive statistics, I pooled all three waves for all the countries together applying external weights (discussed above) and ran several OLS regressions. My decision to pool the countries together was theoretically driven by Pascall and Kwak's (2010) post-socialist gender regime approach that sees the CEE countries in a homogenized way. I regressed GDDL index on time variables (year dummies), class characteristics (respondent's education and household income dummies), interactions of class characteristics with time variables, and a set of control variables to account for compositional changes in the samples over time, as well as for alternative individualand interactional-level explanations. In the last pooled model, I also included country dummies to control for potential national differences in the level of inequality in GDDL and for unobservable variables at the national level that could be correlated with IVs and control variables. Also, I ran country-specific regressions (see Tables 5 and 6 in the Supplementary File) to examine whether the effects of time, class, and other variables on GDDL differed substantially among the analyzed countries.

\section{Results}

\subsection{Descriptive Statistics}

Regional descriptive statistics for the dependent variable are provided in Table 1 (for full regional and countryspecific descriptive statistics see Tables 3 and 4 in the Supplementary File). At the regional level, one could observe an increase in men's relative involvement in the performance of routine housework tasks (GDDL index increasing) between 1994 and 2012. This finding is in line with the results of aggregate-level analyses for the 1994-2002 period discussed above (Crompton \& Lyonette, 2007; Saxonberg, 2014).

Analysis of group-specific means of GDDL by respondent's education and household income, however, suggests that the patterns and trends of GDDL were different for these groups. While in less-educated households the level of men's relative involvement in routine housework appears to have remained unchanged between 1994 and 2012, in the highly-educated households-in which it was already substantially higher in 1994-it seems to have increased throughout that period, primarily between 1994 and 2002. The aggregate increase in equality in GDDL over the analyzed period, thus, appears to have been primarily driven by highly-educated households. Descriptive statistics also suggest that richer households had more equal GDDL than poorer ones al- 
Table 1. Descriptive statistics, dependent variable, CEE Region $(N=11,730)$.

\begin{tabular}{|c|c|c|c|c|c|c|c|c|}
\hline & \multicolumn{4}{|c|}{1994} & \multicolumn{2}{|l|}{2002} & \multicolumn{2}{|l|}{2012} \\
\hline & Min & Max & $M$ & $S D$ & $M$ & $S D$ & M & $S D$ \\
\hline Index of GDDL & -6 & 6 & $\begin{array}{c}-3.25^{\mathrm{a}} \\
{[-3.30 ;-3.19]}\end{array}$ & 1.83 & $\begin{array}{c}-3.17 \\
{[-3.24 ;-3.10]}\end{array}$ & 2.14 & $\begin{array}{c}-3.07 \\
{[-3.14 ;-3.00]}\end{array}$ & 2.16 \\
\hline - low educated & -6 & 6 & $\begin{array}{c}-3.42 \\
{[-3.50 ;-3.34]}\end{array}$ & 1.90 & $\begin{array}{c}-3.52 \\
{[-3.63 ;-3.41]}\end{array}$ & 2.14 & $\begin{array}{c}-3.41 \\
{[-3.55 ;-3.27]}\end{array}$ & 2.18 \\
\hline - highly educated & -6 & 6 & $\begin{array}{c}-2.91 \\
{[-3.05 ;-2.77]}\end{array}$ & 1.70 & $\begin{array}{c}-2.62 \\
{[-2.79 ;-2.44]}\end{array}$ & 2.19 & $\begin{array}{c}-2.60 \\
{[-2.74 ;-2.46]}\end{array}$ & 2.13 \\
\hline - poor/bottom income quintile & -6 & 6 & $\begin{array}{c}-3.39 \\
{[-3.51 ;-3.27]}\end{array}$ & 1.86 & $\begin{array}{c}-3.61 \\
{[-3.76 ;-3.46]}\end{array}$ & 2.06 & $\begin{array}{c}-3.33 \\
{[-3.49 ;-3.17]}\end{array}$ & 2.13 \\
\hline - rich/top income quintile & -6 & 6 & $\begin{array}{c}-3.08 \\
{[-3.19 ;-2.96]}\end{array}$ & 1.73 & $\begin{array}{c}-2.80 \\
{[-2.95 ;-2.65]}\end{array}$ & 2.10 & $\begin{array}{c}-2.87 \\
{[-3.03 ;-2.71]}\end{array}$ & 2.10 \\
\hline
\end{tabular}

Notes: All values are weighted using a combination of external weights and post-stratification weights provided by the ISSP. ${ }^{\text {a } 95 \% \text { con- }}$ fidence intervals for dependent variable in brackets.

ready in 1994. The income gradient of inequality in GDDL appears to have further significantly increased during the first post-socialist decade. While high-income households in that period managed to decrease inequality in GDDL, in low-income households the opposite appears to have occurred. By 2012, however, the income gradient appears to have narrowed again due to an increase in men's relative involvement in routine housework in poorer households and, possibly, some decrease of such involvement in richer ones.

Descriptive statistics do not take into account significant compositional changes, such as education, employment, or breadwinning that can be related to GDDL. Only multivariate analysis, thus, could shed light on trends in GDDL net of individual- and interactional-level factors.

\subsection{Determinants of GDDL, 1994-2012}

Models 1-5 (Table 2) highlight the factors of GDDL at the regional level, with a specific focus on time and class effects. The models have relatively low $R^{2}$, which is in line with what has already been shown in the literature (Fuwa, 2004; Mikucka, 2009)-conventional individualand interactional-level theories of GDDL have less explanatory power in the CEE region. It is important to note, however, that adding class variables and accounting for the changing effect of these variables over time through the use of interaction terms improves the model's explanatory power.

Model 1 captures the aggregate change in the levels of inequality in GDDL at the regional level over time. In this model, I use only a basic set of controls (gender, age, age squared, and size of the household), and the results mirror the findings from the descriptive analysis. Men's relative involvement in routine housework increased between 1994 and 2012. In Model 2, I introduce education and household income variables. Model 2 suggests that the level of education and the level of household income have a significant positive effect on the level of equality in GDDL in the CEE region.

In Model 3, I add variables accounting for partners' employment statuses, their relative incomes, and respondents' gender ideology, which allow me to both account for alternative theoretical explanations and control for compositional changes in my sample over time. Importantly, the effects of education and household income in Model 3 only slightly diminish in comparison with Model 2. Model 3, contrary to Hypothesis 1, suggests that, controlling for individual- and interactionallevel characteristics, there were no statistically significant changes in men's relative involvement in routine housework during the 1990s and the 2000s.

In Model 4, in which I introduce the interactions of education and household income variables with time variables, however, a more complex picture of (the lack of) change emerges. Model 4 clearly shows that changes in GDDL were very class-specific. In line with Hypothesis $2 a$, the educational gradient, which had already been significant in 1994, significantly increased during the 1990s and remained at that level during the 2000s. Income gradient, which was insignificant in 1994, increased significantly by 2002 but disappeared again during the 2000s. Hypothesis $2 \mathrm{~b}$ is thus confirmed for the 1994-2002 period but rejected for 2002-2012.

Model 4 also allows understanding which class processes underlay changes in the gradients. Education/ income group-specific change is calculated by summing the end of the period year coefficient and that specific group-year interaction term (for a similar approach see Treas, Lui, \& Gubernskaya, 2014). In the 1990s, all the other parameters kept constant, lower-educated households experienced a significant decrease in men's relative involvement in routine housework, while highereducated ones did not. During the 2000s, the persistence of the educational gradient was related to a different process. In that period, equality increased among all educa- 
Table 2. Determinants of GDDL, CEE region, 1994-2012 (pooled data, OLS).

\begin{tabular}{|c|c|c|c|c|c|c|c|c|c|c|}
\hline & \multicolumn{2}{|c|}{ Model 1} & \multicolumn{2}{|c|}{ Model 2} & \multicolumn{2}{|c|}{ Model 3} & \multicolumn{2}{|c|}{ Model 4} & \multicolumn{2}{|c|}{ Model 5} \\
\hline & $\beta$ & $(S E)$ & $B$ & $(S E)$ & $\beta$ & $(S E)$ & $\beta$ & $(S E)$ & $\beta$ & $(S E)$ \\
\hline \multicolumn{11}{|l|}{ Year (ref. category: 1994) } \\
\hline 2002 & 0.07 & $(0.04)$ & 0.05 & $(0.04)$ & 0.02 & $(0.04)$ & $-0.36 * * *$ & $(0.11)$ & $-0.34 * *$ & $(0.11)$ \\
\hline 2012 & $0.14^{* *}$ & $(0.05)$ & 0.07 & $(0.05)$ & 0.03 & $(0.05)$ & -0.02 & $(0.12)$ & -0.02 & $(0.12)$ \\
\hline \multicolumn{11}{|c|}{ Education (ref. category: Low Education) } \\
\hline Medium Education & & & $0.25 * * *$ & $(0.04)$ & $0.21 * * *$ & $(0.04)$ & $0.14 *$ & $(0.07)$ & $0.14 *$ & $(0.07)$ \\
\hline Higher Education & & & $0.63 * * *$ & $(0.06)$ & $0.53 * * *$ & $(0.06)$ & $0.34 * * *$ & $(0.10)$ & $0.34 * * *$ & $(0.10)$ \\
\hline Medium Education*2002 & & & & & & & $0.20 *$ & $(0.10)$ & $0.18^{+}$ & $(0.10)$ \\
\hline Higher Education*2002 & & & & & & & $0.27^{+}$ & $(0.14)$ & $0.24^{+}$ & $(0.14)$ \\
\hline Medium Education*2012 & & & & & & & 0.02 & $(0.11)$ & 0.02 & $(0.11)$ \\
\hline Higher Education*2012 & & & & & & & $0.29 *$ & $(0.14)$ & $0.27^{+}$ & $(0.14)$ \\
\hline \multicolumn{11}{|l|}{ Income (ref. category: Low Income) } \\
\hline Medium household income & & & $0.16^{* *}$ & $(0.06)$ & $0.14 *$ & $(0.06)$ & 0.04 & $(0.08)$ & 0.03 & $(0.10)$ \\
\hline High household income & & & $0.22 * * *$ & $(0.07)$ & $0.16^{*}$ & $(0.07)$ & 0.07 & $(0.11)$ & 0.06 & $(0.11)$ \\
\hline Medium household income*2002 & & & & & & & $0.27^{*}$ & $(0.12)$ & $0.28^{*}$ & $(0.12)$ \\
\hline High household income*2002 & & & & & & & $0.38^{*}$ & $(0.16)$ & $0.39 *$ & $(0.16)$ \\
\hline Medium household income*2012 & & & & & & & 0.02 & $(0.14)$ & 0.02 & $(0.14)$ \\
\hline High household income*2012 & & & & & & & -0.10 & $(0.18)$ & -0.10 & $(0.18)$ \\
\hline \multicolumn{11}{|c|}{ Man's employment status (ref. category: full-time) } \\
\hline Man employed part-time & & & & & $0.25^{*}$ & $(0.11)$ & $0.25^{*}$ & $(0.11)$ & $0.26^{*}$ & $(0.11)$ \\
\hline Man not employed & & & & & $0.18 * *$ & $(0.06)$ & $0.19 * * *$ & $(0.06)$ & $0.16 * *$ & $(0.06)$ \\
\hline \multicolumn{11}{|c|}{ Woman's employment status (ref. category: full-time) } \\
\hline Woman employed part-time & & & & & 0.03 & $(0.08)$ & 0.03 & $(0.08)$ & 0.05 & $(0.08)$ \\
\hline Woman not employed & & & & & $-0.31 * * *$ & $(0.05)$ & $-0.31 * * *$ & $(0.05)$ & $-0.33 * * *$ & $(0.05)$ \\
\hline Woman's income share bigger & & & & & $0.34 * * *$ & $(0.05)$ & $0.34 * * *$ & $(0.05)$ & $0.33 * * *$ & $(0.05)$ \\
\hline
\end{tabular}


Table 2. (Cont.) Determinants of GDDL, CEE region, 1994-2012 (pooled data, OLS)

\begin{tabular}{|c|c|c|c|c|c|c|c|c|c|c|}
\hline & \multicolumn{2}{|c|}{ Model 1} & \multicolumn{2}{|c|}{ Model 2} & \multicolumn{2}{|c|}{ Model 3} & \multicolumn{2}{|c|}{ Model 4} & \multicolumn{2}{|c|}{ Model 5} \\
\hline & $\beta$ & $(S E)$ & $B$ & $(S E)$ & $\beta$ & $(S E)$ & $\beta$ & $(S E)$ & $\beta$ & $(S E)$ \\
\hline Egalitarian gender role attitudes ${ }^{a}$ & & & & & $0.03^{* * *}$ & $(0.01)$ & $0.03 * * *$ & $(0.01)$ & $0.02 * * *$ & $(0.01)$ \\
\hline Female respondent & $-0.61 * * *$ & $(0.04)$ & $-0.61 * * *$ & $(0.04)$ & $-0.63 * * *$ & $(0.04)$ & $-0.63 * * *$ & $(0.04)$ & $-0.63 * * *$ & $(0.04)$ \\
\hline Age $^{a}$ & $-0.04 * *$ & $(0.01)$ & $-0.06 * * *$ & $(0.01)$ & $-0.08 * * *$ & $(0.01)$ & $-0.08 * * *$ & $(0.01)$ & $-0.08 * * *$ & $(0.01)$ \\
\hline Age squared & $0.02^{+}$ & $(0.01)$ & $0.05^{* * *}$ & $(0.01)$ & $0.07 * * *$ & $(0.02)$ & $0.07 * * *$ & $(0.01)$ & $0.07 * * *$ & $(0.02)$ \\
\hline Household size ${ }^{a}$ & $-0.11 * * *$ & $(0.02)$ & $-0.09 * * *$ & $(0.02)$ & $-0.07 * * *$ & $(0.02)$ & $-0.07 * * *$ & $(0.02)$ & $-0.08 * * *$ & $(0.02)$ \\
\hline \multicolumn{11}{|l|}{ Country (ref. category: Russia) } \\
\hline Bulgaria & & & & & & & & & -0.02 & $(0.06)$ \\
\hline Czechia & & & & & & & & & -0.10 & $(0.07)$ \\
\hline Hungary & & & & & & & & & $0.16^{*}$ & $(0.07)$ \\
\hline Poland & & & & & & & & & 0.03 & $(0.07)$ \\
\hline Slovenia & & & & & & & & & $0.26 * * *$ & $(0.07)$ \\
\hline Intercept & \multicolumn{2}{|c|}{$-2.85 * * *$} & \multicolumn{2}{|c|}{$-3.24 * * *$} & \multicolumn{2}{|c|}{$-3.20 * * *$} & \multicolumn{2}{|c|}{$-3.06 * * *$} & \multicolumn{2}{|c|}{$-3.10 * * *$} \\
\hline Adjusted $R^{2}$ & \multicolumn{2}{|c|}{0.031} & \multicolumn{2}{|c|}{0.046} & \multicolumn{2}{|c|}{0.063} & \multicolumn{2}{|c|}{0.065} & \multicolumn{2}{|c|}{0.068} \\
\hline F for change in $R^{2}$ & \multicolumn{2}{|c|}{$58.46^{* * *}$} & \multicolumn{2}{|c|}{$44.55^{* * *}$} & \multicolumn{2}{|c|}{$34.46 * * *$} & \multicolumn{2}{|c|}{$3.57 * * *$} & \multicolumn{2}{|c|}{$7.77 * * *$} \\
\hline
\end{tabular}


tional groups (model with 2002 as a reference category is not shown). But in highly educated households the increase was much steeper than among the rest. All the other parameters kept constant, highly-educated households in 2012 had more equal GDDL than in 1994. For the less educated, the levels of GDDL index in 2012 were not statistically different from 1994.

The appearance of income gradient by 2002 and its subsequent disappearance by 2012 was driven primarily by changes in GDDL in poor households. Between 1994 and 2002, men's relative involvement in routine housework among poorer households decreased. Between 2002 and 2012 (model with 2002 as a reference category is not shown), however, it increased back to the 1994 levels. All other parameters kept constant, richer households did not experience statistically significant changes in GDDL, neither in the 1990s nor in the 2000s, although data suggest that there might have been an increase in inequality among high-income households in the 2000s. These findings suggest that the trajectory of change implied in Hypothesis 1 (initial decrease of equality, followed by a subsequent increase) was characteristic of lower classes only.

In Model 5, I add country dummies. I use Russia, a country where the state-socialist gender regime originated from, as a reference category. The effects of all independent variables and controls are robust to the inclusion of country dummies. Coefficients of only two country dummies, i.e., Slovenia and Hungary, are statistically significantly different from the reference category.

Country-specific regressions (see Tables 5 and 6 in the Supplementary File) show that trajectories of net change in GDDL were quite diverse among the analyzed countries. Only Hungary and Bulgaria experienced a net change in GDDL in line with Hypothesis 1, i.e., an initial overall increase in inequality followed by an overall decrease during the 2000s. In the remaining countries, there was either no change in either decade (as in Czechia); an initial decrease of inequality was followed by a subsequent increase (Poland and Russia); or a decrease was followed by stagnation (Slovenia). Notably, however, by 2012 , most of the countries (with the possible exception of Bulgaria and Slovenia) had the same level of inequality in GDDL as in 1994.

Idiosyncratic trends of inequality in GDDL among different classes observed at the regional level, however, characterized developments in all analyzed countries, even if to different extents. In line with Hypothesis $2 a$, over the post-socialist period, the positive effect of education on the level of men's involvement in routine housework increased in all countries except Russia (where it, nevertheless, remained positive). Only in Slovenia did the effect of education eventually disappear between 2002 and 2012, since lower-educated there caught up with higher-educated. As for household income, during the first post-socialist decade, its importance as a factor of more equal GDDL increased in all countries of the region (except Slovenia), primarily due to (stronger) decreases in men's involvement in routine housework among the poor. Between 2002 and 2012, however, in all countries except Russia, the income gradient either significantly diminished or even reversed.

\section{Discussion and Conclusion}

My first hypothesis-that, net of individual and interactional-level factors, inequality in GDDL in the CEE countries increased during the first post-socialist decade and subsequently decreased during the 2000s-received confirmation in two countries only. Analysis of trends of inequality for different classes, however, showed that this was a rather typical trajectory for lower-class households across most of the analyzed countries. This finding partially supports a view established in the literature that gender inequalities increased in the early years of post-socialist transition (Ashwin, 2006; Pine, 2002; Pollert, 2003), but points out an often-overlooked classspecificity of this argument.

My hypothesis about the increased positive effect of education on equality in GDDL received confirmation at the regional level and across most of the countries. However, contrary to the theoretical assumption that an increase in educational gradient would be driven by highly-educated embracing more egalitarian patterns of GDDL first (Sullivan, 2010), at least between 1994-2002 across most of CEE this was not the case. In that period, the gradient increased primarily due to increased inequality in GDDL among lower-educated. Only in 2002-2012 was the persistence of educational gradient in several countries, indeed, related to the relatively faster change towards greater equality among highly-educated, as was suggested in the Western contexts (Sullivan, 2010). This finding emphasizes the importance of applying a class lens to the post-socialist re-traditionalization argument, as has been already pointed out by anthropologists working on the region (e.g., Kalb, 2018).

Finally, my hypothesis about the increased positive effect of household income on equality in GDDL was confirmed in relation to the 1994-2002 period across most of the countries. However, contrary to my expectation, an increase in income gradient was driven primarily not by the rich, but rather by the poor experiencing a significant reduction in equality in GDDL. The latter was probably caused by the impact that welfare retrenchment and economic crises had on volumes of unpaid work within poorer households, as was shown in ethnographic studies (e.g., Pine, 2002). Indeed, in the 2000s when the countries entered a period of economic growth and welfare expansion, the trend for the poor also reversed.

The principal limitations of this study stem from the nature of the data used for the analysis. First, the focus of the research was on the relative distribution of the burden of routine housework and equality within the couple rather than on time use. Second, using 1994 as a starting point for analysis of post-socialist transition could have resulted in an underestimation of the extent of changes 
in the first post-socialist decade, as by that moment the countries analyzed had already been 'in transition' for 3-5 years. Thirdly, this data does not allow to account for the effects of the 2008-2009 financial crisis, which has been shown to have had some negative gendered impacts in several of the analyzed countries (Szalma \& Takács, 2013). Finally, having information on both partners' education would have likely improved the fit of the model, taking into account the impact of educational homogamy on GDDL (Esping-Andersen, 2009).

In conclusion, it is important to note some insights that the experience of post-socialist CEE offers to the wider study of GDDL. First, the findings of this study lend further support to the claims made recently in the scholarship on change in GDDL about the need to consider the extent of stall and progress for different sociodemographic groups (Sullivan et al., 2018). As shown, in CEE, class represents an important explanatory factor which must be accounted for if we are to understand the lack of progress on equality in GDDL in the region in the post-socialist period. This lack of progress was primarily related to significant setbacks in gender equality among the lower-class households during the period of market transition in the 1990s, which they only managed to offset during the 2000s. Second, my findings highlight the importance of considering changes in GDDL among lower classes not only as a result of 'catching up' with trends emanating from higher classes (Sullivan, 2010), but also as a consequence of their greater vulnerability to impacts of socio-economic crises that may lead to increases in shares of unpaid work carried out by women. Finally, this study provides empirical evidence that household income may have a positive effect on relative gender equality in the division of domestic labor (cf. Heisig, 2011). It, however, also demonstrates that this effect may be a temporary phenomenon. Further studies are needed to reveal the exact mechanisms underlying this relation.

\section{Acknowledgments}

This research was carried out as part of an ongoing doctoral project funded by a scholarship granted by the Bremen International Graduate School of Social Sciences (BIGSSS) to the author. The author wishes to thank Sonja Drobnic, Olaf Groh Samberg, Eva Fodor, Ania Plomien, Sarah Ashwin, doctoral students at BIGSSS and the LSE Department of Gender Studies, Michael Ochsner, Ivett Szalma, Judit Takács, and two anonymous peer reviewers for their feedback.

\section{Conflict of Interests}

The author declares no conflict of interests.

\section{Supplementary Material}

Supplementary material for this article is available online in the format provided by the author (unedited).

\section{References}

Aassve, A., Fuochi, G., \& Mencarini, L. (2014). Desperate housework: Relative resources, time availability, economic dependency, and gender ideology across Europe. Journal of Family Issues, 35(8), 1000-1022. https://doi.org/10.1177/0192513X14522248

Aboim, S. (2010). Gender cultures and the division of labour in contemporary Europe: A cross-national perspective. Sociological Review, 58(2), 171-196. https://doi.org/10.1111/j.1467-954X.2010.01899.x

Altintas, E., \& Sullivan, O. (2016). Fifty years of change updated: Cross-national gender convergence in housework. Demographic Research, 35(August), 455-470. https://doi.org/10.4054/DemRes.2016.35.16

Ashwin, S. (2006). The post-Soviet gender order: Imperatives and implications. In S. Ashwin (Ed.), Adapting to Russia's new labour market: Gender and employment behaviour (pp. 30-51). London and New York, NY: Routledge.

Balabanova, E. S. (2005). Domashnyi trud kak simvol gendera i vlasti [Domestic labor as a symbol of gender and power]. Sotsiologicheskie Issledovaniya, 2005(6), 109-120.

Beneria, L., Berik, G., \& Floro, M. S. (2015). Gender, development and globalization: Economics as if all people mattered (2nd ed.). London and New York, NY: Routledge.

Bianchi, S. M., \& Milkie, M. A. (2010). Work and family research in the first decade of the 21st century. Journal of Marriage and Family, 72(3), 705-725. https:// doi.org/10.1111/j.1741-3737.2010.00726.x

Bianchi, S. M., Milkie, M. A., Sayer, L. C., \& Robinson, J. P. (2000). Is anyone doing the housework? Trends in the gender division of household labor. Social Forces, 79(1), 191-228.

Bittman, M., England, P., Sayer, L., Folbre, N., \& Matheson, G. (2003). When does gender trump money? Bargaining and time in household work. American Journal of Sociology, 109(1), 186-214. https://doi. org/10.1086/378341

Crompton, R., Brockmann, M., \& Lyonette, C. (2005). Attitudes, women's employment and the domestic division of labour: A cross-national analysis in two waves. Work, Employment \& Society, 19(2), 213-233. https://doi.org/10.1177/0950017005053168

Crompton, R., \& Lyonette, C. (2007). Occupational class, country and the domestic division of labour. In R. Crompton, S. Lewis, \& C. Lyonette (Eds.), Women, men, work and family in Europe (pp. 116-132). Basingstoke \& New York, NY: Palgrave Macmillan.

Davis, S. N., \& Greenstein, T. N. (2004). Cross-national variations in the division of household labor. Journal of Marriage and Family, 66(5), 1260-1271.

Davis, S. N., \& Wills, J. B. (2014). Theoretical explanations amid social change: A content analysis of housework research. Journal of Family Issues, 35(6), 808-824. https://doi.org/10.1177/0192513X13513020 
Drobnič, S., \& Ruppanner, L. (2015). Gender inequalities in the home. Emerging Trends in the Social and Behavioral Sciences. https://doi.org/10.1002/ 9781118900772.etrds0141

Einhorn, B. (1993). Cinderella goes to market: Citizenship, gender and women's movements in East Central Europe. London and New York, NY: Verso.

Esping-Andersen, G. (2009). The incomplete revolution: Adapting to women's new roles. Cambridge: Polity.

Evertsson, M., \& Nermo, M. (2007). Changing resources and the division of housework: A longitudinal study of Swedish couples. European Sociological Review, 23(4), 455-470. https://doi.org/10.1093/esr/jcm018

Fuwa, M. (2004). Macro-level gender inequality and the division of household labor in 22 countries. American Sociological Review, 69(6), 751-767. https://doi.org/ $10.1177 / 000312240406900601$

Gal, S., \& Kligman, G. (2000). The politics of gender after socialism. Princeton, NJ: Princeton University Press.

Gapova, E. (2002). On nation, gender and class formation in Belarus...and elsewhere in the post-Soviet world. Nationalities Papers, 30(4), 639-662. https:// doi.org/10.1080/00905992.2002.10540511

Geist, C., \& Cohen, P. N. (2011). Headed toward equality? Housework change in comparative perspective. Journal of Marriage and Family, 73(4), 832-844. https:// doi.org/10.1111/j.1741-3737.2011.00850.x

Gershuny, J. (2000). Changing times: Work and leisure in postindustrial society. Oxford: Oxford University Press.

Gupta, S., Evertsson, M., Grunow, D., Nermo, M., \& Sayer, L. C. (2010). Economic inequality and housework. In S. Drobnič \& J. Treas (Eds.), Dividing the domestic. Men, women and household work in cross-national perspective (pp. 105-122). Stanford, CA: Stanford University Press.

Heisig, J. P. (2011). Who does more housework: Rich or poor? A comparison of 33 countries. American Sociological Review, 76(1), 74-99. https://doi.org/ 10.1177/0003122410396194

Hook, J. L. (2006). Care in context: Men's unpaid work in 20 countries, 1965-2003. American Sociological Review, 71, 639-660.

Hook, J. L. (2010). Gender inequality in the welfare state: Sex segregation in housework, 1965-2003. American Journal of Sociology, 115(5), 1480-1523. https://doi. org/10.1086/651384

Humer, Z., \& Hrznjak, M. (2015). When the state steps in: An experiment of subsidised hiring of domestic worker in Slovenia. In S. Marchetti \& A. Triandafyllidou (Eds.), Employers, agencies and immigration: Paying for care (pp. 169-189). Farnham and Burlington, NJ: Ashgate.

Johnson, D. R., \& Young, R. (2011). Toward best practices in analyzing datasets with missing data: Comparisons and recommendations. Journal of Marriage and Family, 73(5), 926-945. https://doi.org/10.1111/j.17413737.2011.00861.x
Kalb, D. (2018). Upscaling illiberalism: Class, contradiction, and the rise and rise of the populist right in postsocialist Central Europe. Fudan Journal of the Humanities and Social Sciences, 11(3), 1-19. https://doi.org/ 10.1007/s40647-018-0221-3

Kan, M. Y., Sullivan, O., \& Gershuny, J. (2011). Gender convergence in domestic work: Discerning the effects of interactional and institutional barriers from large-scale data. Sociology, 45(2), 234-251. https:// doi.org/10.1177/0038038510394014

Klenner, C., \& Leiber, S. (2010). Introduction: Welfare states and gender in transformation. In C. Klenner \& S. Leiber (Eds.), Welfare states and gender in Central and Eastern Europe: Continuity and post-socialist transformation in the EU Member States (pp. 9-32). Brussels: European Trade Union Institute.

Kunovich, R. M., \& Kunovich, S. (2008). Gender dependence and attitudes toward the distribution of household labor: A comparative and multilevel analysis. International Journal of Comparative Sociology, 49(6), 395-427. https://doi.org/10.1177/ 0020715208097787

Lapidus, G. (1978). Women in Soviet society: Equality development and social change. Berkley, CA: University of California Press.

Lee, Y. S., \& Waite, L. J. (2005). Husbands' and wives' time spent on housework: A comparison of measures. Journal of Marriage and Family, 67(2), 328-336. https://doi.org/10.1111/j.0022-2445.2005.00119.x

Lobodzinska, B. (1977). Married women' gainful employment and housework in contemporary Poland. Journal of Marriage and the Family, 39, 405-415.

Mikucka, M. (2009). Division of household labor between spouses: How do Central and Eastern Europe differ from the West? International Journal of Sociology, 39(1), 76-94. https://doi.org/10.2753/IJS00207659390105

Motiejunaite, A., \& Kravchenko, Z. (2008). Family policy, employment and gender-role attitudes: A comparative analysis of Russia and Sweden. Journal of European Social Policy, 18(1), 38-49. https://doi.org/ 10.1177/0958928707084453

Nikolic-Ristanovic, V. (2002). Social change, gender and violence: Post-communist and war affected societies. Dordrecht: Springer Science+Business Media.

Pascall, G., \& Kwak, A. (2010). Gender regimes in transition: Gender equality in CEE countries? In C. Klenner \& S. Leiber (Eds.), Welfare states and gender in Central and Eastern Europe: Continuity and postsocialist transformation in the EU Member States (pp. 117-150). Brussels: European Trade Union Institute.

Pine, F. (2002). Retreat to the household? Gendered domains in postsocialist Poland. In C. Hann (Ed.), Postsocialism. Ideals, Ideologies and Practices in Euroasia (pp. 95-113). London and New York, NY: Routledge. https://doi.org/10.4324/9780203428115

Pollert, A. (2003). Women, work and equal opportunities in post-communist transition. Work, Employment 
\& Society, 17(2), 331-357. https://doi.org/10.1177/ 0950017003017002006

Redlová, P. (2012). Employment of Filipinas as nannies in the context of post-socialist Czech Republic. Urban People, 2, 185-215.

Rotkirch, A., Tkach, O., \& Zdravomyslova, E. (2012). Making and managing class: Employment of paid domestic workers in Russia. In S. Salmenniemi (Ed.), Rethinking class in Russia (pp. 129-148). Farnham and Burlington, NJ: Ashgate.

Salmeniemi, S. (2012). Rethinking class in Russia. In S. Salmenniemi (Ed.), Rethinking class in Russia (pp. 1-22). Farnham and Burlington, NJ: Ashgate.

Saxonberg, S. (2014). Gendering family policies in postcommunist Europe: A historical-institutional analysis. Basingstoke and New York, NY: Palgrave Macmillan.

Schneider, D., \& Hastings, O. (2017). Income inequality and household labor. Social Forces, 96(2), 481-506. https://doi.org/10.17605/OSF.IO/PWNY5

Sullivan, O. (2010). Changing differences by educational attainment in fathers' domestic labour and child care. Sociology, 44(4), 716-733. https://doi.org/10.1177/ 0038038510369351

Sullivan, O., Gershuny, J., \& Robinson, J. P. (2018). Stalled or uneven gender revolution? A long-term processual framework for understanding why change is slow. Journal of Family Theory \& Review, 10(1), 263-279. https://doi.org/10.1111/jftr.12248

Szalma, I., \& Takács, J. (2013). Should men have more rights...? Gender-role-related attitudes before and during the 2008 crisis. In G. Johnsson \& K. Stefansson (Eds.), Retrenchment or renewal? Welfare states in times of economic crisis (pp. 207-233). Helsinki: Nordic Centre of Excellence Nordwel.

Takács, J. (2013). Unattainable desires? Childbearing capabilities in early $21^{\text {st }}$ century Hungary. In L. S. Olah \& E. Fratczak (Eds.), Childbearing, women's employment and work-life balance policies in contemporary Europe (pp. 179-206). Basingstoke and New York, NY: Palgrave Macmillan.

Treas, J., Lui, J., \& Gubernskaya, Z. (2014). Attitudes on marriage and new relationships: Cross-national evidence on the deinstitutionalization of marriage. Demographic Research, 30(1), 1495-1526. https://doi. org/10.4054/DemRes.2014.30.54

Treas, J., \& Tai, T. (2012). Apron strings of working mothers: Maternal employment and housework in crossnational perspective. Social Science Research, 41(4), 833-842. https://doi.org/10.1016/j.ssresearch.2012. 01.008

Treas, J., \& Tai, T. (2016). Gender inequality in housework across 20 European nations: Lessons from gender stratification theories. Sex Roles, 74, 495-511. https://doi.org/10.1007/s11199-015-0575-9

Watson, P. (1993). The rise of masculinism in Eastern Europe. New Left Review, 1993(May), 71-82.

West, C., \& Zimmermann, D. H. (1987). Doing gender. Gender \& Society, 1(2), 125-151. https://doi.org/ 10.1017/СBO9781107415324.004

\section{About the Author}

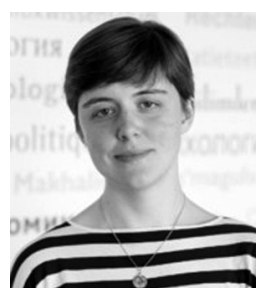

Daria Ukhova is currently completing a PhD in Sociology at the Bremen International Graduate School of Social Sciences, Germany. In her mixed methods dissertation, she explores how class shapes gender division of unpaid work in post-socialist Europe, with a particular focus on Russia. Prior to starting her $\mathrm{PhD}$, Daria worked for a number of years in various research and policy roles at Oxfam and WHO. 